\title{
Review Article \\ Red Orange: Experimental Models and Epidemiological Evidence of Its Benefits on Human Health
}

\author{
Giuseppe Grosso, ${ }^{1,2}$ Fabio Galvano, ${ }^{2}$ Antonio Mistretta, ${ }^{1}$ \\ Stefano Marventano, ${ }^{1}$ Francesca Nolfo, ${ }^{1}$ Giorgio Calabrese, ${ }^{3}$ Silvio Buscemi, ${ }^{4}$ \\ Filippo Drago, ${ }^{5}$ Umberto Veronesi, ${ }^{6}$ and Alessandro Scuderi ${ }^{7}$ \\ ${ }^{1}$ Section of Hygiene and Public Health, Department of G.F. Ingrassia, University of Catania, Via S. Sofia No. 85-95123, Catania, Italy \\ ${ }^{2}$ Section of Biochemistry, Department of Drug Sciences, University of Catania, Catania, Italy \\ ${ }^{3}$ Department of Biology, Piemonte Orientale University, Alessandria, Italy \\ ${ }^{4}$ Department of Internal Medicine, University of Palermo, Palermo, Italy \\ ${ }^{5}$ Section of Pharmacology and Biochemistry, Department of Clinical and Molecular Biomedicine, \\ University of Catania, Catania, Italy \\ ${ }^{6}$ Department of Experimental Medicine, University of Rome "Sapienza", Rome, Italy \\ ${ }^{7}$ Department of Agri-Food and Environmental Systems and Management (DIGESA), University of Catania, Catania, Italy
}

Correspondence should be addressed to Giuseppe Grosso; giuseppe.grosso@studium.unict.it

Received 27 February 2013; Accepted 10 April 2013

Academic Editor: Narasimham L. Parinandi

Copyright (C) 2013 Giuseppe Grosso et al. This is an open access article distributed under the Creative Commons Attribution License, which permits unrestricted use, distribution, and reproduction in any medium, provided the original work is properly cited.

In recent years, there has been increasing public interest in plant antioxidants, thanks to the potential anticarcinogenic and cardioprotective actions mediated by their biochemical properties. The red (or blood) orange (Citrus sinensis (L.) Osbeck) is a pigmented sweet orange variety typical of eastern Sicily (southern Italy), California, and Spain. In this paper, we discuss the main health-related properties of the red orange that include anticancer, anti-inflammatory, and cardiovascular protection activities. Moreover, the effects on health of its main constituents (namely, flavonoids, carotenoids, ascorbic acid, hydroxycinnamic acids, and anthocyanins) are described. The red orange juice demonstrates an important antioxidant activity by modulating many antioxidant enzyme systems that efficiently counteract the oxidative damage which may play an important role in the etiology of numerous diseases, such as atherosclerosis, diabetes, and cancer. The beneficial effects of this fruit may be mediated by the synergic effects of its compounds. Thus, the supply of natural antioxidant compounds through a balanced diet rich in red oranges might provide protection against oxidative damage under differing conditions and could be more effective than, the supplementation of an individual antioxidant.

\section{Introduction}

In recent years, an increasing interest in plant antioxidants has occurred because of the potential anticarcinogenic and cardioprotective actions mediated by their biochemical properties [1-3]. The antioxidant activity of these compounds may be dependent on the number and arrangement of the hydroxyl groups and the extent of structural conjugation, as well as the presence of electron-donating and electronwithdrawing substituents in the ring structure. Due to the growing interest in these pharmacologically active components in fruits, the demand for studies conducted on specific fruit such as pigmented orange juice is increasing.

Red (or blood) orange (Citrus sinensis (L.) Osbeck) is a pigmented sweet orange variety typical of eastern Sicily (southern Italy), California, and Spain. The red orange is noteworthy for its excellent orange flesh color and the consistent appearance of red coloration. The red coloration of red orange is mostly caused by the presence of water-soluble anthocyanin pigments not usually found in other citrus fruits. 
In this paper, we discuss the main health-related properties of red orange that include anticancer, anti-inflammatory, and cardiovascular protection activities, and the effects on health of the main constituents of the red orange (namely, flavonoids, carotenoids, ascorbic acid, hydroxycinnamic acids, and anthocyanins) and their antioxidant activity and ability to modulate some key regulatory enzymes.

\section{History, Geographical Distribution, and Varieties of Red Oranges}

Red oranges may have originated from either China or the southern Mediterranean regions, but their exact origin is not known. It is possible that, in China, northeastern India, and southeastern Asia, Citrus sinensis trees were eventually transported along Asian trade routes to Africa, the Mediterranean Sea Basin, and Europe where orangeries were established. A mosaic in a Roman villa built in the first quarter of the 4 th century and located about $3 \mathrm{~km}$ outside the town of Piazza Armerina, Sicily (southern Italy), demonstrates the presence of lime and lemon in Italy in that period of time. Citrus fruit seems to have been introduced in Sicily by Arab traders during the 7th century and cultivated as ornament until the 16th century. Spaniards introduced orange cultivation in South America in the 1500s and from there also in the United States. The first description of the red orange in Sicily was noted in the 17th century opera Hesperides (1646). The author described a particular kind of orange fruit ("aurantium inducum"), which is strongly pigmented ("purpurei coloris medulla"), imported to the island by a Genoese missionary from the Philippines islands.

The three most common types of red oranges are the Tarocco, the Moro (both native to Italy), and the Sanguinello (native to Spain). Other less common types include Budd blood orange, Maltese, Khanpur, Washington Sanguine, Ruby Blood, Sanguina Doble Fina, Delfino, Red Valencia, Burris blood Valencia orange, Vaccaro blood orange, Sanguine grosse ronde, Entre Fina blood orange, and Sanguinello a pignu. While also pigmented, Cara Cara Navels and Vaniglia Sanguignos have pigmentation based on lycopene, not anthocyanins like blood oranges [4]. The Tarocco variety is a medium-sized seedless fruit and is perhaps the sweetest and most flavorful of the three types. It is referred to as "half-blood," because the flesh is not accentuated in red pigmentation as much as with the Moro and Sanguinello varieties. The Moro is the most colorful of the red oranges, referred to as "deep blood orange," with deep red flesh ranges from orange-veined with ruby coloration, to vermilion, to vivid crimson, and nearly to black and a rind that has a bright red blush. This fruit has a distinct, sweet flavor with a hint of raspberry. The Moro variety is believed to have originated at the beginning of the 19th century in the citrus-growing area around Lentini (in the Province of Siracusa in Sicily) as a bud mutation of the "Sanguinello Moscato." The Sanguinello variety, discovered in Spain in 1929, is also present in Sicily as a "full-blood" orange, close in characteristics to the Moro. It matures in February, but can remain on trees unharvested until April. Fruit can last until the end of May.

\section{The Anti-Inflammatory Capacity of Red Orange Juice}

Red orange juice contains elevated quantities of various compounds including polyphenols, flavanones, anthocyanins, hydroxycinnamic acids, and ascorbic acid, and it is supposed to have a high antioxidant capacity depending on all its components (Table 1). After determining the antioxidant profile of several fresh orange juices obtained from five different Citrus sinensis (L.) Osbeck varieties (three pigmented varieties: Moro, Sanguinello, and Tarocco, and two blond varieties, Valencia late and Washington navel), the antioxidant efficiency of orange juices has been attributed, in a significant part at least, to their content of total phenols, whereas ascorbic acid seems to play a minor role [5]. In vivo studies conducted on healthy people has shown that red orange juice consumption determines a significant increase in plasma vitamin C, cyanidin-3-glucoside, beta-cryptoxanthin, and zeaxanthin [6]. The effect of red orange juice has been studied also in 19 subjects with increased cardiovascular risk included in a randomized, placebo-controlled, single-blind crossover study and compared with 12 healthy, nonobese control subjects in which consumption of red orange juice ameliorated endothelial functions, improving flow-mediated dilation and reducing inflammation [7].

The antioxidant activity of orange juices is related not only to structural features of phytochemicals but also to their capability to interact with biomembranes [5]. The quality control of cultivation and characteristic freshness of red oranges have demonstrated their active influence on total antioxidant activity and bioactivity of such fruit. The antioxidant capacity of red orange has been explored in two orange-based products: first, pasteurized pure juice with 40 days of shelf life, and, the second, a sterilized beverage containing minimum $12 \%$ of concentrated fruit juice [8]. Results obtained revealed that the antioxidant activity was positively related to the content of anthocyanins and the reduction of their content, typical of commercial long-shelf life juices, leading to a remarkable loss of antioxidant power. Similar results were obtained comparing both the phytochemical content (i.e., phenolics, anthocyanins, and ascorbic acid), total antioxidant activity and in vitro bioactivity, in terms of the protective effect obtained against oxidative damage at cellular level with organically and nonorganically grown red oranges in cell culture systems [9]. The organic orange extracts showed a higher total antioxidant activity than non-organic orange extracts due to their higher content of total phenolics, total anthocyanins, and ascorbic acid levels than the corresponding nonorganic oranges.

Red orange intake (especially Moro juice) has been found to limit body weight gain, enhance insulin sensitivity, and decrease serum triglycerides and total cholesterol in mice [10, 11]. Dietary Moro juice markedly improved liver steatosis by inducing the expression of peroxisome proliferator-activated receptor- $\alpha$ and its target gene acylCoA-oxidase, a key enzyme of lipid oxidation. Consistently, Moro juice consumption suppressed the expression of liver X receptor- $\alpha$ and its target gene fatty acid synthase, and restored liver glycerol-3-phosphate acyltransferase 1 activity [10]. This action on fat accumulation 
TABLE 1: Main components of red orange fruit.

\begin{tabular}{|c|c|}
\hline Food components & Value \\
\hline \multicolumn{2}{|l|}{ Proximates } \\
\hline Energy, recalculated, kJ & 144 \\
\hline Energy, recalculated, kcal & 34 \\
\hline Total protein, $g$ & 0.7 \\
\hline Animal protein, $\mathrm{g}$ & 0.0 \\
\hline Vegetable protein, $g$ & 0.7 \\
\hline Total fat, $g$ & 0.2 \\
\hline Animal fat, $g$ & 0.0 \\
\hline Vegetable fat, $g$ & 0.2 \\
\hline Cholesterol, mg & 0 \\
\hline Available carbohydrates, $g$ & 7.8 \\
\hline Starch, g & 0.0 \\
\hline Soluble carbohydrates, $g$ & 7.8 \\
\hline Dietary total fibre, $g$ & 1.6 \\
\hline Alcohol, g & 0.0 \\
\hline Water, g & 87.2 \\
\hline \multicolumn{2}{|l|}{ Minerals and traces elements } \\
\hline Iron, mg & 0.2 \\
\hline Calcium, mg & 49 \\
\hline Sodium, mg & 3 \\
\hline Potassium, mg & 200 \\
\hline Phosphorus, mg & 22 \\
\hline Zinc, mg & 0.20 \\
\hline \multicolumn{2}{|l|}{ Water soluble vitamins } \\
\hline Vitamin B1, thiamin, mg & 0.06 \\
\hline Vitamin B2, riboflavin, mg & 0.05 \\
\hline Vitamin C, mg & 50 \\
\hline Niacin, mg & 0.20 \\
\hline Vitamin B6, mg & 0.10 \\
\hline Total folate, $\mu \mathrm{g}$ & 31 \\
\hline Retinol eq., $\mu \mathrm{g}$ & 71 \\
\hline Retinol, $\mu \mathrm{g}$ & 0 \\
\hline$\beta$-Carotene eq., $\mu \mathrm{g}$ & 426 \\
\hline Vitamin E, $\alpha$-tocopherol eq., mg & 0.24 \\
\hline Vitamin D, $\mu \mathrm{g}$ & 0.00 \\
\hline \multicolumn{2}{|l|}{ Fatty Acids } \\
\hline Saturated fatty acids, $g$ & 0.03 \\
\hline Monounsaturated fatty acids, $g$ & 0.04 \\
\hline Oleic acid, g & 0.03 \\
\hline Polyunsaturated fatty acids, $g$ & 0.04 \\
\hline Linoleic acid, $g$ & 0.03 \\
\hline Linolenic acid, g & 0.01 \\
\hline
\end{tabular}

Source: European Institute of Oncology (EIO) database at http://www.ieo.it/ bda2008/homepage.aspx.

has been demonstrated to be mediated by the insulin-like effect of anthocyanins cyanidin-3-O- $\beta$-glucoside $(\mathrm{C} 3 \mathrm{G})$ and its metabolite protocatechuic acid (PCA) [12]. However, the Moro juice antiobesity effect on fat accumulation cannot be explained only by its anthocyanin content and multiple components present in the red orange juice that might act synergistically to inhibit fat accumulation. Likewise, the antiinflammatory effects of red orange juice do not depend only on a single component [5]. An experimental study has demonstrated that the intake of a single portion of red orange juice provides an early protection of the mononuclear red cell against oxidative DNA damage, whereas, on the contrary, no subsequent effect of a drink supplemented with the same amount of vitamin $\mathrm{C}$ was observed [13]. Thus, the protective effect of red orange juice was not explained by utilization of vitamin $\mathrm{C}$ alone. Therefore, a variety of phytochemicals contained in red oranges are assumed to be involved.

\section{Components of Red Orange}

4.1. Flavonoids. Polyphenols are a group of chemical substances found in plants, especially in the genus Citrus, characterized by the presence of more than one phenol unit [14]. The most commonly studied polyphenols are the flavonoids, which include several thousand compounds, characterized by a common benzo- $\gamma$-pyrone structure [14]. Flavones, flavonols, anthocyanins and, in greater quantities, flavanones are four types of flavonoids present in Citrus, in concentration dependent on age of the plant and directly proportional to its mitotic activity [14]. The relatively large number of flavonoids in Citrus juices is a result of the many different combinations that are possible between polyhydroxylated aglycones and a limited number of mono- and disaccharides (Table 2). The most abundant flavonoid species that have been so far identified and quantified in Citrus sinensis, regardless of variety, is by far hesperidin, followed by narirutin and didymin [15] These are all flavanone-O-glycosides, which account for most of the flavonoid content in juice, although a higher content has been found in red orange varieties (Sanguinello, Moro, and Tarocco) compared with nonpigmented variants (Navel, Valencia, and Ovale) [16].

The antioxidant properties of flavonoids protect by oxidative stress induced by both reactive oxygen species (ROS) and reactive nitrogen species (RNS) that have been shown to play a role in initiation and progression of CVD and atherosclerosis (Table 3). Several studies suggest that flavonoids act through several mechanisms on the NO-guanylyl cyclase pathway, endothelium derived hyperpolarizing factor(s), and endothelin-1, protecting endothelial cells inducing vasorelaxation [17]. Other evidence suggests that prevention of endothelial dysfunction, blood pressure, and oxidative stress reduction are the main actions of flavonoids $[18,19]$. Their mechanism of action seems to be explained by some in vitro studies in which flavonoids interacted with various enzyme systems involved in cellular signaling, such as cyclo-oxygenases and lipoxygenases, phosphodiesterases, tyrosine kinases, and phospholipases [20]. These compounds also protect lowdensity lipoproteins (LDL) against macrophages-induced oxidation by preventing the generation of lipid hydroperoxides and to preserve R-tocopherol, an endogenous antioxidant carried in lipoproteins [21,22].

Flavonoids have been demonstrated to be able to inhibit the growth of some tumors, such as colon [23], oral cancer [24], human breast cancer cells [25], lung carcinoma [26], and different melanoma cell lines, in which there have been 
TABLE 2: Main polyphenols contained in red orange juice.

\begin{tabular}{|c|c|c|c|c|c|}
\hline Polyphenol group & Single component & Mean content & $\min$ & $\max$ & $\mathrm{SD}$ \\
\hline \multicolumn{6}{|l|}{ Flavonoids } \\
\hline \multirow{2}{*}{ Anthocyanins } & Cyanidin 3-O-glucoside & $1.41 \mathrm{mg} / 100 \mathrm{~mL}$ & 0.28 & 4.03 & 1.32 \\
\hline & $\begin{array}{c}\text { Cyanidin } \\
3-\mathrm{O}-\left(6^{\prime \prime} \text {-malonyl-glucoside }\right)\end{array}$ & $1.76 \mathrm{mg} / 100 \mathrm{~mL}$ & 0.37 & 3.86 & 1.30 \\
\hline \multirow{4}{*}{ Flavanones } & Hesperidin & $43.61 \mathrm{mg} / 100 \mathrm{~mL}$ & 18.00 & 66.50 & 17.98 \\
\hline & Narirutin & $4.80 \mathrm{mg} / 100 \mathrm{~mL}$ & 2.90 & 6.46 & 1.28 \\
\hline & Didymin & $2.43 \mathrm{mg} / 100 \mathrm{~mL}$ & 0.89 & 3.53 & 1.27 \\
\hline & Sinensetin & $0.26 \mathrm{mg} / 100 \mathrm{~mL}$ & 0.26 & 0.26 & 0.00 \\
\hline \multirow[t]{2}{*}{ Flavones } & Nobiletin & $0.31 \mathrm{mg} / 100 \mathrm{~mL}$ & 0.31 & 0.31 & 0.00 \\
\hline & Tangeretin & $0.04 \mathrm{mg} / 100 \mathrm{~mL}$ & 0.04 & 0.04 & 0.00 \\
\hline Flavonols & 3-Methoxynobiletin & $0.08 \mathrm{mg} / 100 \mathrm{~mL}$ & 0.08 & 0.08 & 0.00 \\
\hline \multicolumn{6}{|l|}{ Phenolic acids } \\
\hline \multirow{6}{*}{ Hydroxycinnamic acids } & Cinnamoyl glucose & $1.50 \mathrm{mg} / 100 \mathrm{~mL}$ & 0.41 & 3.74 & 1.50 \\
\hline & Cinnamic acid & $0.02 \mathrm{mg} / 100 \mathrm{~mL}$ & $7.00 e-03$ & 0.06 & 0.03 \\
\hline & p-Coumaric acid & $2.92 \mathrm{mg} / 100 \mathrm{~mL}$ & 1.24 & 4.46 & 0.84 \\
\hline & Caffeic acid & $0.88 \mathrm{mg} / 100 \mathrm{~mL}$ & 0.44 & 1.51 & 0.34 \\
\hline & Ferulic acid & $4.40 \mathrm{mg} / 100 \mathrm{~mL}$ & 3.16 & 6.37 & 0.75 \\
\hline & Sinapic acid & $1.74 \mathrm{mg} / 100 \mathrm{~mL}$ & 1.01 & 3.59 & 0.63 \\
\hline
\end{tabular}

Source: phenol-explorer at http://www.phenol-explorer.eu/.

TABLE 3: Name, effect, and mechanisms of action of main components of red orange.

\begin{tabular}{|c|c|c|}
\hline Food components & Effect & Mechanisms of action \\
\hline \multirow{5}{*}{ Flavonoid } & Anti-inflammatory & $\begin{array}{l}\text { Modulate apoB secretion and cellular cholesterol; help cholesterol levels by raising HDL } \\
\text { and lowering LDL cholesterol }\end{array}$ \\
\hline & Antioxidant & Stimulate endothelial NO synthase; normalize lipid peroxidation markers \\
\hline & Antiaggregation & Inhibit TxA2-mediated responses and dense granule secretion \\
\hline & Anticarcinogenic & $\begin{array}{l}\text { Promote apoptosis in human pre-B NALM- } 6 \text { cells and colon cancer cells; inhibit HIF-1 } \alpha \\
\text { and VEGF expression in ovarian cancer and in lung cancer }\end{array}$ \\
\hline & Antiproliferative & $\begin{array}{l}\text { Inhibit the COX-2 and MMPs in lung, prostate, and hepatocellular carcinoma cells; } \\
\text { inhibited the proliferation of MCF-7 human breast cancer cells and testosterone-induced } \\
\text { proliferation of LNCaP cells; inhibit lung colonization by melanoma and sarcoma cell } \\
\text { line; inhibit formation of new blood vessels in human breast cancer cells }\end{array}$ \\
\hline \multirow{3}{*}{ Anthocyanins } & Antioxidant & $\begin{array}{l}\text { Protect biomembranes from peroxidation by trapping peroxyl radicals in the cytosol; } \\
\text { chelate metal ions like } \mathrm{Cu} 2 \text {; ability in chelating metal ions like } \mathrm{Cu} 2 \text {; form an ascorbic acid } \\
\text { metal-anthocyanin complex (copigment) }\end{array}$ \\
\hline & Antimutagenicity & $\begin{array}{l}\text { Form a cyanidin-DNA copigmentation complex; inhibit the reverse mutation induced by } \\
\text { heterocyclic amines in microsomal activation systems }\end{array}$ \\
\hline & Growth inhibition & $\begin{array}{l}\text { Inhibit the tyrosine kinase activity of the EGFR and the activation of the GAL4-Elk-1 } \\
\text { fusion protein }\end{array}$ \\
\hline Carotenoids & Antioxidant & React with singlet molecular oxygen and peroxyl radicals \\
\hline \multirow[b]{2}{*}{ Vitamin C } & Blow-flow increase & $\begin{array}{l}\text { Enhance generation of NO; reduce nitrite; stabilize atherosclerotic plaques (due to effect } \\
\text { on collagen synthesis) }\end{array}$ \\
\hline & Antioxidant & $\begin{array}{l}\text { Reduce the affinity of LDL-bound apoB protein for transition metal ions; quench aqueous } \\
\text { ROS and RNS, decreasing their bioavailability in the plasma; reduce potentially damaging } \\
\text { ROS, forming resonance-stabilized and relatively stable ascorbate free radicals; attenuate } \\
\text { LDL-oxidation and protection of human vascular smooth muscle cells against apoptosis }\end{array}$ \\
\hline \multirow{2}{*}{ Hydroxycinnamic acids } & Antioxidant & $\begin{array}{l}\text { Effect on phase II detoxification cascade; inhibit of superoxide dismutase and catalase; } \\
\text { suppress of PG synthesis and cyclooxygenase- } 2\end{array}$ \\
\hline & Anticarcinogenic & $\begin{array}{l}\text { Prevent the tumor onset and protect the biochemical and molecular abnormalities in } \\
\text { mammary, buccal pouch, colon, and skin cancers }\end{array}$ \\
\hline
\end{tabular}

EGFR: epidermal growth-factor receptor; HDL: high-density lipoproteins; HIF-1 $\alpha$ : hypoxia-inducible factor $1 \alpha$; LDL: low-density lipoproteins; MMP: matrix metalloproteinase; NO: nitric oxide; PG: prostaglandins; RNS: reactive nitrogen species; ROS: reactive oxygen species. 
demonstrated the antiproliferative effects but not the cytotoxic activity $[27,28]$. Several flavonoids actions have been explored as possible mechanisms able to explain their anticarcinogenic effects, such as inhibition of matrix metalloproteinase (MMP) secretion, migration, invasion, and adhesion [29-33], as well as inhibition of the angiogenic process by regulating the expression of vascular endothelial growth factor (VEGF) and hypoxia-inducible factor $1 \alpha$ (HIF-1 $\alpha$ ) [3436], all factors required by cancer cells to acquire metastatic properties. Some citrus flavonoids have been suggested to have potential health benefits due to their proapoptotic activity on several cancer cell lines, thus inhibiting progression of carcinogenesis [37-40].

4.2. Anthocyanins. Anthocyanins are a group of watersoluble plant compounds responsible for the brilliant color of fruits and flowers [41]. They are glycosylated polyhydroxy and polymethoxy derivatives of flavylium salts. The first experimental observation of anthocyanins in red orange was in 1931 by Matlack that demonstrated their presence in citrus fruits, "the red-fleshed variety, the so-called blood orange" [42] confirming a statement noticed even 15 years before [43]. Fruits subjected to thermal stress produce a greater amount of protective substances (i.e., anthocyanins) necessary to guard against unfavorable environmental conditions. The composition of Anthocyanins can be analyzed as a parameter for the assessment of authenticity and quality of foods rich in anthocyanin pigments $[44,45]$. Several studies carried out on red oranges have shown that cyanidin-3-glycoside (C3G) was the main component of the fraction [46]. Some differences in anthocyanins content may occur considering different types of red oranges. Indeed, the primary anthocyanins in Budd blood orange, a red-colored blood orange typically grown in Florida, USA, were inverted in content, cyanidin-3- $\left(6^{\prime \prime}\right.$ malonylglucoside) (44.8\%) followed by cyanidin-3-glucoside (33.6\%). Vegetables and fruits, with special regard to pigmented oranges, such as Moro, Sanguinello, and Tarocco varieties, represent a natural source of anthocyanins, especially cyanidins [2]. Each cultivar shows a characteristic seasonal variation of the content of anthocyanins: the cultivar Moro contains the highest amount of anthocyanins, with a maximum peak at the first half of April; cultivars Tarocco shows the highest value in the first decade of March; cultivar Sanguinello Nocellare and Sanguinello show the lowest values of anthocyanins with the maximum values in the end of February and in the first half of March, respectively [41].

The antioxidant properties of anthocyanins, and especially of the C3G, depend on their radical scavenging and inhibitory effects on lipid peroxidation $[2,47]$ by their strong oxygen radical absorbance capacity (ORAC) and nitric oxide (NO) and cyclooxygenase inhibitory activities [48-50] (Table 3). Given the unstable nature of anthocyanins under natural conditions, it was believed that such molecules would not have antioxidant activity in living systems but many studies, instead, have demonstrated the antioxidant activity of C3G also in in vivo experiments [51]. The protection against oxidative damage of anthocyanins was observed as a dose-dependent decrease of ROS-mediated tissue damages after different C3G administration in living systems such as isolated Langendorff-perfused rat hearts subjected to ischemia and reperfusion [52], rat liver, kidneys, and brain [53], rabbit erythrocyte membranes, and rat liver microsomes [54]. In rats maintained on vitamin-E-deficient diets for 12 weeks in order to enhance susceptibility to oxidative damage, consumption of dietary anthocyanins significantly improved plasma antioxidant capacity, decreased the vitamin E deficiency, and enhanced hydroperoxides concentrations in liver [47]. These properties seem to be due to the cyanidin structure that allows the compound to be incorporated into the plasma membrane and cytosol of endothelial cells significantly enhancing their resistance to the damaging effects caused by several ROS-generating systems [55]. The antioxidant activity of orally administered C3G in rats was demonstrated in a model for acute oxidative stress in which C3G significantly suppressed the elevations of the liver and serum thiobarbituric-acid-reactive substance concentrations and the serum activities of marker enzymes for liver injury (GOT, GPT, and LDH) caused by hepatic ischemia-reperfusion treatment [56]. It has been suggested only in recent years that orally administered C3G is absorbed into the circulating system as a free form and subsequently metabolized to protocatechuic acid or peonidin 3-glucoside in the blood and tissues [57], and these compounds act as antioxidants in rats [58]. In vivo formation of protocatechuic acid following administration of C3G has been demonstrated in three species (humans, rats, and pigs), although protocatechuic acid is not retrieved in blood in $100 \%$ of cases due to differences in the experimental models (namely storage conditions, preanalytical treatments of biological samples and extraction procedure) that may affect its fugitive nature [59]. The bioavailability and biotransformation issues have to be always considered when the health efficacy of compounds from oral administration on target organs is considered. Further research should be focused not only on consequent anthocyanins effects but also on their metabolites, rather than their native forms, that reach tissues and may exert biological effects.

A number of biological activities of anthocyanins aimed at preventing cancer have been addressed [60-62]. The antimutagenic activity was demonstrated by a study on colorectal carcinogenesis inducted by 1,2-dimethylhydrazine (DMH) [63] confirming previous reports in which juice or extracts of plants containing large amounts of anthocyanins acted as inhibitors of heterocyclic amine mutagenesis [64, 65]. C3G also prevented genomic DNA damage in human fibroblast [66], hepatoma-derived cell line (Hep G2) [67], colonic adenocarcinoma (CaCo-2) [68], melanoma [69], and vulva carcinoma A431 [70] cell lines. Finally, experiments on protocatechuic acid have been demonstrated promising curative properties in its use against colon cancer [71-73].

4.3. Carotenoids. Fruits and vegetables are a rich source in this phytochemicals and almost 50 carotenoids can be found in the human diet [74]. The carotenoids that have been most studied in this regard are $\alpha$-carotene, $\beta$-carotene, lycopene, lutein, $\beta$-cryptoxanthin, and zeaxanthin, almost all contained in red orange in higher quantities than in other sweet oranges (only Cara Cara orange demonstrated a superior contents 
of carotenoids compared with Sanguinello) [75]. Carotenoids have been implicated as important dietary nutrients having many other biological functions such as antioxidant activity, being involved in the scavenging of free radicals. Moreover, carotenoids react with singlet molecular oxygen and peroxyl radicals generated in the process of lipid peroxidation and they have been shown to protect LDL against oxidation (Table 3) [76].

In addition to their antioxidant properties, carotenoids show an array of biological effects including cardioprotective, antimutagenic and anticarcinogenic activities, involving modulation of signal transduction pathways and induction of gap-junctional communication. Dietary intakes of carotenoids have been associated with decreased risk of coronary artery disease [77], CVD [78, 79], atherosclerosis [80]. Lutein plasma changes have been associated with more promising early outcomes and decreased lipid peroxidation in subjects after ischemic stroke [81, 82], reduced risk of ischemic stroke [83]. By contrast, the risk reductions in cardiovascular events subsequent to high carotenoid intakes have appeared only to a small degree [84] or not confirmed in other studies $[85,86]$. During the post-intervention followup, dietary supplementation with alpha-tocopherol or betacarotene has produced neither any benefit nor harm [87]. After an average of four years of supplementation, the combination of beta carotene and vitamin A showed no benefits and may even have had an adverse effect on health, with an increased risk of death cause, lung cancer, and CVD [88]. Finally, evidence resulting from a recent randomized controlled trial on specific antioxidant supplementation was insufficient to prove the effectiveness of each of the vitamin supplements in preventing or treating cardiovascular disease [89]. To date, more information is needed to clarify the relation between the intake of single carotenoids, and the risk of heart diseases.

4.4. Ascorbic Acid (Vitamin C). Vitamin C, or ascorbic acid, serves in humans as a co-factor in several important enzyme reactions and is necessary for the synthesis of collagen [90]. Due to the incapacity to synthesize vitamin C, humans require it from natural sources through supplements to the ordinary diet. Lack of vitamin C results in scurvy, a pathological condition characterized by friable vessels, especially in capillary tissues that are most likely to rupture, and also petechial hemorrhages and ecchymosis due to a deficit of collagen synthesis and secretion to form the extracellular matrix or part of the basement membrane [90]. The vitamin C content of red oranges is in the range of 32 to $42 \mathrm{mg}$ per $100 \mathrm{~mL}$, with the highest levels found in the Sanguinello varieties, followed by Cara Cara navels and Moro (the US recommended daily allowance for vitamin $\mathrm{C}$ is set at $75 \mathrm{mg}$ for women and $90 \mathrm{mg}$ for men) [46].

At physiological concentrations, vitamin $\mathrm{C}$ is a potentfree radical scavenger in plasma, protecting cells against oxidative damage caused by ROS (Table 3) [91]. The antioxidant property of ascorbic acid is attributed to its ability to reduce potentially damaging ROS, forming, instead, resonance-stabilized and relatively stable ascorbate free radicals [92]. These antioxidant capacities lead to numerous effects of vitamin C on vascular bed, such as induction of endothelial-dependent artery dilation and increase of blood flow [93], attenuation of in vitro and in vivo LDL-oxidation [94-96], and protection of human vascular smooth muscle cells against apoptosis $[97,98]$. In light of the several benefits of vitamin $\mathrm{C}$ on endothelial cell proliferation, function, and viability, it is plausible that increases in plasma and cell content of such vitamins might help to prevent, delay, or stabilize early endothelial dysfunction associated with atherosclerosis.

Several studies hypothesized that the anti-inflammatory properties of Vitamin C may reduce the incidence of many malignancies in humans due to a number of cytoprotective functions under physiological conditions, including prevention of DNA mutation induced by oxidation by neutralizing potentially mutagenic ROS [99-102]. Indeed, consumption of vitamin-C-rich foods has been found to be inversely related to the level of oxidative DNA damage in vivo [103]. However, the inconsistency of the vitamin C cancer correlation and lack of validated mechanistic basis for its therapeutic action underline its potential role as a preventive rather than therapeutic drug.

4.5. Hydroxycinnamic Acids. Hydroxycinnamic acids (hydroxycinnamates) are a class of polyphenols having a C6C3 skeleton. These compounds are hydroxy derivatives of cinnamic acid. In the category of phytochemicals that can be found in red orange, the most common are caffeic, pcoumaric, ferulic, and sinapic [104]. Free and bound ferulic acid represent the major component in all cases, followed by p-coumaric acid, sinapic acid, and caffeic acid. However, hydroxycinnamic acids have been found to be more abundant in red orange than in blond juices. Ferulic acids and caffeic acid are among the most studied hydroxycinnamic acids (Table 3).

Ferulic acid is an abundant phenolic phytochemical found in plant cell wall components such as arabinoxylans as is found, for instance, in covalent side chains. It is related to trans-cinnamic acid. As a component of lignin, ferulic acid is a precursor in the manufacture of other aromatic compounds. It has been demonstrated to be successfully employed as topical protective agents against UV radiation-induced skin damage after in vitro and in vivo evaluation [105], often in combination with other antioxidants such caffeic acid [106] and vitamin C [107]. Its mechanisms of action may depend on preventing DNA damage and restoring antioxidant status and histopathological changes [108]. The anticarcinogenic properties of ferulic acid have been studied on mammary [109], buccal pouch [110], colon [111], and skin [112] carcinogenesis in experimental models findings showing that oral administration of ferulic acid significantly prevented the onset of tumors and the biochemical and molecular abnormalities. Although the exact chemopreventive mechanism of the ferulic acid is unclear, its antigenotoxic and antioxidant potentials as well as modulatory effect on phase II detoxification cascade could play a possible role [109].

Caffeic acid is an organic compound that is classified as a hydroxycinnamic acid. This acid consists of both phenolic and acrylic functional groups. It is found in all plants because 
it is a key intermediate in the biosynthesis of lignin, one of the principal sources of biomass [113]. The caffeic acid phenethyl ester has been found to be a potent free radical scavenger [114] and studied for its antioxidant capacities in several experimental rat models on renal impairment [115-117], retinal oxidative stress [118], myocardial oxidative stress [119], age-related vascular remodeling and cardiac damage [120], and the same time helping to prevent the metabolic consequences in diabetes mellitus $[121,122]$, erythrocyte membrane ischemia/reperfusion injury [123], cerebral damage induced by ischemia reperfusion [124], and oxidative stress [125]. The mechanisms by which caffeic acid phenethyl ester exerts its anti-inflammatory action seems to depend on its effect on lipid peroxidation (LPO) and the inhibition of antioxidant enzymes such as superoxide dismutase and catalase [126]. Moreover, caffeic acid phenethyl ester has also been shown to cause dose-dependent suppression of prostaglandins synthesis suppressing the expression of cyclooxygenase- 2 in cultured human oral epithelial cells and in an animal model of acute inflammation [127] and in the protection of mice from lethal endotoxin shock. It also inhibits lipopolysaccharide-induced cyclooxygenase- 2 and inducible NO synthase expression in RAW 264.7 macrophages via the p38/ERK and NF- $\kappa \mathrm{B}$ pathways, therefore providing mechanistic insights into the anti-inflammatory and chemopreventive actions of caffeic acid phenethyl ester in macrophages [128].

\section{Conclusions}

On the basis of these findings, evidence has shown that red oranges demonstrate both potent antioxidant activity and also cytoprotective effects that reflect their substantial role in preventing chronic pathological conditions such as cardiovascular diseases and in many forms of cancers. A synergic action between organic farming and social activities may amplify the advantages and reciprocal benefits in order to obtain a "social and environmental sustainability" and spread consumption of healthy products $[129,130]$. The supply of natural antioxidant compounds through a balanced diet rich in red oranges might provide protection against oxidative damage under different conditions and could be more effective than supplementation of an individual antioxidant.

\section{Acknowledgments}

Giuseppe Grosso and Fabio Galvano equally contributed to the paper. Giuseppe Grosso was supported by the International Ph.D. Program in Neuropharmacology, University of Catania Medical School, Catania, Italy. The funders had no role in the study design, data collection, analysis, decision to, or preparation of the paper.

\section{References}

[1] F. Galvano, L. La Fauci, G. Lazzarino et al., "Cyanidins: metabolism and biological properties," Journal of Nutritional Biochemistry, vol. 15, no. 1, pp. 2-11, 2004.
[2] A. M. Amorini, G. Fazzina, G. Lazzarino et al., "Activity and mechanism of the antioxidant properties of cyanidin-3-O- $\beta$ glucopyranoside," Free Radical Research, vol. 35, no. 6, pp. 953966, 2001.

[3] F. Galvano, F. Salamone, A. Nicolosi, and P. Vitaglione, "Anthocyanins-based drugs for colon cancer treatment: the nutritionist's point of view," Cancer Chemotherapy and Pharmacology, vol. 64, no. 2, pp. 431-432, 2009.

[4] W. Reuther, D. B. Leon, and J. W. Herbert, Horticultural Varieties of Citrus, 1967.

[5] P. Rapisarda, A. Tomaino, R. Lo Cascio, F. Bonina, A. de Pasquale, and A. Saija, "Antioxidant effectiveness as influenced by phenolic content of fresh orange juices," Journal of Agricultural and Food Chemistry, vol. 47, no. 11, pp. 4718-4723, 1999.

[6] P. Riso, F. Visioli, C. Gardana et al., "Effects of blood orange juice intake on antioxidant bioavailability and on different markers related to oxidative stress," Journal of Agricultural and Food Chemistry, vol. 53, no. 4, pp. 941-947, 2005.

[7] S. Buscemi, G. Rosafio, G. Arcoleo et al., "Effects of red orange juice intake on endothelial function and inflammatory markers in adult subjects with increased cardiovascular risk," The American Journal of Clinical Nutrition, vol. 95, no. 5, pp. 1089-1095, 2012.

[8] A. Fiore, L. La Fauci, R. Cervellati et al., "Antioxidant activity of pasteurized and sterilized commercial red orange juices," Molecular Nutrition and Food Research, vol. 49, no. 12, pp. 11291135, 2005.

[9] A. Tarozzi, S. Hrelia, C. Angeloni et al., "Antioxidant effectiveness of organically and non-organically grown red oranges in cell culture systems," European Journal of Nutrition, vol. 45, no. 3, pp. 152-158, 2006.

[10] F. Salamone, G. Li Volti, L. Titta et al., "Moro orange juice prevents fatty liver in mice," World Journal of Gastroenterology, vol. 18, no. 29, pp. 3862-3868, 2012.

[11] L. Titta, M. Trinei, M. Stendardo et al., "Blood orange juice inhibits fat accumulation in mice," International Journal of Obesity, vol. 34, no. 3, pp. 578-588, 2010.

[12] B. Scazzocchio, R. Varì, C. Filesi et al., "Cyanidin-3-O- $\beta$-glucoside and protocatechuic acid exert insulin-like effects by upregulating PPAR $\gamma$ activity in human omental adipocytes," Diabetes, vol. 60, no. 9, pp. 2234-2244, 2011.

[13] S. Guarnieri, P. Riso, and M. Porrini, “Orange juice vs vitamin C: effect on hydrogen peroxide-induced DNA damage in mononuclear blood cells," The British Journal of Nutrition, vol. 97, no. 4, pp. 639-643, 2007.

[14] O. Benavente-García and J. Castillo, "Update on uses and properties of citrus flavonoids: new findings in anticancer, cardiovascular, and anti-inflammatory activity," Journal of Agricultural and Food Chemistry, vol. 56, no. 15, pp. 6185-6205, 2008.

[15] G. Gattuso, D. Barreca, C. Gargiulli, U. Leuzzi, and C. Caristi, "Flavonoid composition of citrus juices," Molecules, vol. 12, no. 8, pp. 1641-1673, 2007.

[16] A. R. Proteggente, A. Saija, A. de Pasquale, and C. A. RiceEvans, "The compositional characterisation and antioxidant activity of fresh juices from sicilian sweet orange (Citrus sinensis L. Osbeck) varieties," Free Radical Research, vol. 37, no. 6, pp. 681-687, 2003.

[17] S. Rizza, R. Muniyappa, M. Iantorno et al., "Citrus polyphenol hesperidin stimulates production of nitric oxide in endothelial cells while improving endothelial function and reducing inflammatory markers in patients with metabolic syndrome," 
Journal of Clinical Endocrinology and Metabolism, vol. 96, no. 5, pp. E782-E792, 2011.

[18] N. M. Borradaile, L. E. de Dreu, and M. W. Huff, "Inhibition of net HepG2 cell apolipoprotein B secretion by the citrus flavonoid naringenin involves activation of phosphatidylinositol 3-kinase, independent of insulin receptor substrate-1 phosphorylation," Diabetes, vol. 52, no. 10, pp. 2554-2561, 2003.

[19] P. Selvaraj and K. V. Pugalendi, "Hesperidin, a flavanone glycoside, on lipid peroxidation and antioxidant status in experimental myocardial ischemic rats," Redox Report, vol. 15, no. 5, pp. 217-223, 2010.

[20] N. Nandakumar and M. P. Balasubramanian, "Hesperidin a citrus bioflavonoid modulates hepatic biotransformation enzymes and enhances intrinsic antioxidants in experimental breast cancer rats challenged with 7, 12-dimethylbenz (a) anthracene," Journal of Experimental Therapeutics and Oncology, vol. 9, no. 4, pp. 321-335, 2012.

[21] P. Selvaraj and K. V. Pugalendi, "Efficacy of hesperidin on plasma, heart and liver tissue lipids in rats subjected to isoproterenol-induced cardiotoxicity," Experimental and Toxicologic Pathology, vol. 64, no. 5, pp. 449-452, 2012.

[22] E. M. Kurowska, J. A. Manthey, A. Casaschi, and A. G. Theriault, "Modulation of HepG2 cell net apolipoprotein B secretion by the citrus polymethoxyflavone, tangeretin," Lipids, vol. 39, no. 2, pp. 143-151, 2004.

[23] T. Tanaka, H. Kohno, M. Murakami et al., "Suppression of azoxymethane-induced colon carcinogenesis in male F344 rats by mandarin juices rich in $\beta$-cryptoxanthin and hesperidin," International Journal of Cancer, vol. 88, no. 1, pp. 146-150, 2000.

[24] E. G. Miller, J. J. Peacock, T. C. Bourland et al., "Inhibition of oral carcinogenesis by citrus flavonoids," Nutrition and Cancer, vol. 60, no. 1, pp. 69-74, 2008.

[25] J. A. Manthey and N. Guthrie, "Antiproliferative activities of citrus flavonoids against six human cancer cell lines," Journal of Agricultural and Food Chemistry, vol. 50, no. 21, pp. 5837-5843, 2002.

[26] S. Kamaraj, G. Ramakrishnan, P. Anandakumar, S. Jagan, and T. Devaki, "Antioxidant and anticancer efficacy of hesperidin in benzo(a)pyrene induced lung carcinogenesis in mice," Investigational New Drugs, vol. 27, no. 3, pp. 214-222, 2009.

[27] J. Rodriguez, J. Yáñez, V. Vicente et al., "Effects of several flavonoids on the growth of B16F10 and SK-MEL-1 melanoma cell lines: relationship between structure and activity;" Melanoma Research, vol. 12, no. 2, pp. 99-107, 2002.

[28] C. Martínez, J. Yàñez, V. Vicente et al., "Effects of several polyhydroxylated flavonoids on the growth of B16F10 melanoma and Melan-a melanocyte cell lines: influence of the sequential oxidation state of the flavonoid skeleton," Melanoma Research, vol. 13, no. 1, pp. 3-9, 2003.

[29] M. R. Vijayababu, A. Arunkumar, P. Kanagaraj, P. Venkataraman, G. Krishnamoorthy, and J. Arunakaran, "Quercetin downregulates matrix metalloproteinases 2 and 9 proteins expression in prostate cancer cells (PC-3)," Molecular and Cellular Biochemistry, vol. 287, no. 1-2, pp. 109-116, 2006.

[30] W. J. Lee, L. F. Wu, W. K. Chen, C. J. Wang, and T. H. Tseng, "Inhibitory effect of luteolin on hepatocyte growth factor/ scatter factor-induced HepG2 cell invasion involving both MAPK/ERKs and PI3K-Akt pathways," Chemico-Biological Interactions, vol. 160, no. 2, pp. 123-133, 2006.

[31] S. Kamaraj, P. Anandakumar, S. Jagan, G. Ramakrishnan, and T. Devaki, "Modulatory effect of hesperidin on benzo(a)pyrene induced experimental lung carcinogenesis with reference to COX-2, MMP-2 and MMP-9," European Journal of Pharmacology, vol. 649, no. 1-3, pp. 320-327, 2010.

[32] A. Balakrishnan and V. P. Menon, "Effect of hesperidin on matrix metalloproteinases and antioxidant status during nicotine-induced toxicity," Toxicology, vol. 238, no. 2-3, pp. 90-98, 2007.

[33] M. H. Yeh, S. T. Kao, C. M. Hung, C. J. Liu, K. H. Lee, and C. C. Yeh, "Hesperidin inhibited acetaldehyde-induced matrix metalloproteinase-9 gene expression in human hepatocellular carcinoma cells," Toxicology Letters, vol. 184, no. 3, pp. 204-210, 2009.

[34] R. Schindler and R. Mentlein, "Flavonoids and vitamin E reduce the release of the angiogenic peptide vascular endothelial growth factor from human tumor cells," Journal of Nutrition, vol. 136, no. 6, pp. 1477-1482, 2006.

[35] J. Fang, C. Xia, Z. Cao, J. Z. Zheng, E. Reed, and B. H. Jiang, "Apigenin inhibits VEGF and HIF-1 expression via PI3K/AKT/ p70S6K1 and HDM2/p53 pathways," FASEB Journal, vol. 19, no. 3, pp. 342-353, 2005.

[36] L. Z. Liu, J. Fang, Q. Zhou, X. Hu, X. Shi, and B. H. Jiang, "Apigenin inhibits expression of vascular endothelial growth factor and angiogenesis in human lung cancer cells: implication of chemoprevention of lung cancer," Molecular Pharmacology, vol. 68, no. 3, pp. 635-643, 2005.

[37] G. Sivagami, R. Vinothkumar, C. P. Preethy et al., "Role of hesperetin (a natural flavonoid) and its analogue on apoptosis in HT-29 human colon adenocarcinoma cell line-a comparative study," Food and Chemical Toxicology, vol. 50, no. 3-4, pp. 660671, 2012.

[38] A. Ghorbani, M. Nazari, M. Jeddi-Tehrani, and H. Zand, "The citrus flavonoid hesperidin induces p53 and inhibits NF- $\kappa \mathrm{B}$ activation in order to trigger apoptosis in NALM-6 cells: involvement of PPAR $\gamma$-dependent mechanism," European Journal of Nutrition, vol. 51, no. 1, pp. 39-46, 2012.

[39] T. Leonardi, J. Vanamala, S. S. Taddeo et al., "Apigenin and naringenin suppress colon carcinogenesis through the aberrant crypt stage in azoxymethane-treated rats," Experimental Biology and Medicine, vol. 235, no. 6, pp. 710-717, 2010.

[40] H. J. Park, M. J. Kim, E. Ha, and J. H. Chung, "Apoptotic effect of hesperidin through caspase 3 activation in human colon cancer cells, SNU-C4," Phytomedicine, vol. 15, no. 1-2, pp. 147-151, 2008.

[41] L. Mondello, A. Cotroneo, G. Errante, G. Dugo, and P. Dugo, "Determination of anthocyanins in blood orange juices by HPLC analysis," Journal of Pharmaceutical and Biomedical Analysis, vol. 23, no. 1, pp. 191-195, 2000.

[42] M. B. Matlack, "observations on the red color of the blood orange," Plant Physiology, vol. 6, no. 4, pp. 729-730, 1931.

[43] M. Wheldale, "M. the anthocyanin pigments of plants," footnote 1, p. 27, 1916.

[44] V. Hong and R. E. Wrolstad, "Characterization of anthocyanincontaining colorants and fruit juices by HPLC/photodiode array detection," Journal of Agricultural and Food Chemistry, vol. 38, no. 3, pp. 698-708, 1990.

[45] C. Garcia-Viguera, P. Zafrilla, and F. A. Toma’s-Barbera’n, "Determination of authenticity of fruit jams by HPLC analysis of anthocyanins," Journal of the Science of Food and Agriculture, vol. 73, pp. 207-213, 1997.

[46] E. Kafkas, S. Ercisli, K. N. Kemal, K. Baydar, and H. Yilmaz, "Chemical composition of blood orange varieties from Turkey: a comparative study," Pharmacognosy Magazine, vol. 5, no. 20, pp. 329-335, 2009. 
[47] C. Ramirez-Tortosa, O. M. Andersen, L. Cabrita et al., "Anthocyanin-rich extract decreases indices of lipid peroxidation and DNA damage in vitamin E-depleted rats," Free Radical Biology and Medicine, vol. 31, no. 9, pp. 1033-1037, 2001.

[48] J. Wang and G. Mazza, "Inhibitory effects of anthocyanins and other phenolic compounds on nitric oxide production in LPS/IFN- $\gamma$-activated RAW 264.7 macrophages," Journal of Agricultural and Food Chemistry, vol. 50, no. 4, pp. 850-857, 2002.

[49] N. P. Seeram, R. A. Momin, M. G. Nair, and L. D. Bourquin, "Cyclooxygenase inhibitory and antioxidant cyanidin glycosides in cherries and berries," Phytomedicine, vol. 8, no. 5, pp. 362-369, 2001.

[50] V. Sorrenti, F. Mazza, A. Campisi et al., "Heme oxygenase induction by cyanidin-3-O- $\beta$-glucoside in cultured human endothelial cells," Molecular Nutrition and Food Research, vol. 51, no. 5, pp. 580-586, 2007.

[51] F. Galvano, L. La Fauci, P. Vitaglione, V. Fogliano, L. Vanella, and C. Felgines, "Bioavailability, antioxidant and biological properties of the natural free-radical scavengers cyanidin and related glycosides," Annali dell'Istituto Superiore di Sanita, vol. 43, no. 4, pp. 382-393, 2007.

[52] A. M. Amorini, G. Lazzarino, F. Galvano, G. Fazzina, B. Tavazzi, and G. Galvano, "Cyanidin-3-O- $\beta$-glucopyranoside protects myocardium and erythrocytes from oxygen radical-mediated damages," Free Radical Research, vol. 37, no. 4, pp. 453-460, 2003.

[53] C. Di Giacomo, R. Acquaviva, A. Piva et al., "Protective effect of cyanidin 3-O- $\beta$-d-glucoside on ochratoxin A-mediated damage in the rat," The British Journal of Nutrition, vol. 98, no. 5, pp. 937943, 2007

[54] T. Tsuda, M. Watanabe, K. Ohshima et al., "Antioxidative activity of the anthocyanin pigments cyanidin 3-O- $\beta$-D-glucoside and cyanidin," Journal of Agricultural and Food Chemistry, vol. 42, no. 11, pp. 2407-2410, 1994.

[55] K. A. Youdim, A. Martin, and J. A. Joseph, "Incorporation of the elderberry anthocyanins by endothelial cells increases protection against oxidative stress," Free Radical Biology and Medicine, vol. 29 , no. 1, pp. 51-60, 2000.

[56] T. Tsuda, F. Horio, J. Kitoh, and T. Osawa, "Protective effects of dietary cyanidin 3-O- $\beta$-D-glucoside on liver ischemia-reperfusion injury in rats," Archives of Biochemistry and Biophysics, vol. 368, no. 2, pp. 361-366, 1999.

[57] F. Galvano, P. Vitaglione, G. Li Volti et al., "Protocatechuic acid: the missing human cyanidins' metabolite," Molecular Nutrition and Food Research, vol. 52, no. 3, pp. 386-387, 2008.

[58] T. Tsuda, F. Horio, and T. Osawa, "Absorption and metabolism of cyanidin 3-O- $\beta$-D-glucoside in rats," FEBS Letters, vol. 449, no. 2-3, pp. 179-182, 1999.

[59] R. Masella, C. Santangelo, M. D’Archivio, G. Li Volti, and F. Galvano, "Protocatechuic acid and human disease prevention: biological activities and molecular mechanisms," Current Medicinal Chemistry, vol. 19, no. 18, pp. 2901-2917, 2012.

[60] Y. C. Liang, Y. C. Chen, Y. L. Lin, S. Y. Lin-Shiau, C. T. Ho, and J. K. Lin, "Suppression of extracellular signals and cell proliferation by the black tea polyphenol, theaflavin-3,3'-digallate," Carcinogenesis, vol. 20, no. 4, pp. 733-736, 1999.

[61] Y. C. Liang, S. Y. Lin-Shiau, C. F. Chen, and J. K. Lin, "Suppression of extracellular signals and cell proliferation through EGF receptor binding by (-)-epigallocatechin gallate in human A431 epidermoid carcinoma cells," Journal of Cellular Biochemistry, vol. 67 , no. 1, pp. 55-65, 1997.
[62] A. D. Sarma and R. Sharma, "Anthocyanin-DNA copigmentation complex: mutual protection against oxidative damage," Phytochemistry, vol. 52, no. 7, pp. 1313-1318, 1999.

[63] A. Hagiwara, K. Miyashita, T. Nakanishi et al., "Pronounced inhibition by a natural anthocyanin, purple corn color, of 2amino-1-methyl-6-phenylimidazo[4,5-b]pyridine (PhIP)-associated colorectal carcinogenesis in male F344 rats pretreated with 1,2-dimethylhydrazine," Cancer Letters, vol. 171, no. 1, pp. 17-25, 2001.

[64] R. Edenharder, P. Kurz, K. John, S. Burgard, and K. Seeger, "In vitro effect of vegetable and fruit juices on the mutagenicity of 2-amino-3-methylimidazo[4,5-f]quinoline, 2-amino-3,4-dimethylimidazo[4,5-f]quinoline and 2-amino-3,8-dimethylimidazo[4,5-f] quinoxaline," Food and Chemical Toxicology, vol. 32, no. 5, pp. 443-459, 1994.

[65] R. Edenharder, C. Leopold, and M. Kries, "Modifying actions of solvent extracts from fruit and vegetable residues on 2-amino-3methylimidazo[4,5-f] quinoline (IQ) and 2-amino-3,4-dimethylimidazo[4,5-f] quinoxaline (MeIQx) induced mutagenesis in Salmonella typhimurium TA 98," Mutation Research, vol. 341, no. 4, pp. 303-318, 1995.

[66] A. Russo, L. La Fauci, R. Acquaviva et al., "Ochratoxin Ainduced DNA damage in human fibroblast: protective effect of cyanidin 3-O- $\beta$-D-glucoside," Journal of Nutritional Biochemistry, vol. 16, no. 1, pp. 31-37, 2005.

[67] M. C. Guerra, F. Galvano, L. Bonsi et al., "Cyanidin-3-O- $\beta$-glucopyranoside, a natural fee-radical scavenger against aflatoxin B1-and ochratoxin A-induced cell damage in a human hepatoma cell line (Hep G2) and a human colonic adenocarcinoma cell line (CaCo-2)," The British Journal of Nutrition, vol. 94, no. 2, pp. 211-220, 2005.

[68] M. Renis, L. Calandra, C. Scifo et al., "Response of cell cycle/stress-related protein expression and DNA damage upon treatment of $\mathrm{CaCo} 2$ cells with anthocyanins," The British Journal of Nutrition, vol. 100, no. 1, pp. 27-35, 2008.

[69] A. Serafino, P. Sinibaldi-Vallebona, G. Lazzarino et al., "Differentiation of human melanoma cells induced by cyanidin-3-O$\beta$-glucopyranoside," FASEB Journal, vol. 18, no. 15, pp. 19401942,2004

[70] S. Meiers, M. Kemény, U. Weyand, R. Gastpar, E. von Angerer, and D. Marko, "The anthocyanidins cyanidin and delphinidin are potent inhibitors of the epidermal growth-factor receptor," Journal of Agricultural and Food Chemistry, vol. 49, no. 2, pp. 958-962, 2001.

[71] H. H. Lin, J. H. Chen, C. C. Huang, and C. J. Wang, "Apoptotic effect of 3,4-dihydroxybenzoic acid on human gastric carcinoma cells involving JNK/p38 MAPK signaling activation," International Journal of Cancer, vol. 120, no. 11, pp. 2306-2316, 2007.

[72] Q. Zheng, Y. Hirose, N. Yoshimi et al., "Further investigation of the modifying effect of various chemopreventive agents on apoptosis and cell proliferation in human colon cancer cells," Journal of Cancer Research and Clinical Oncology, vol. 128, no. 10, pp. 539-546, 2002.

[73] H. Mori, T. Tanaka, S. Sugie et al., "Chemoprevention by naturally occurring and synthetic agents in oral, liver, and large bowel carcinogenesis," Journal of Cellular Biochemistry, vol. 27, pp. 35-41, 1997.

[74] M. C. Polidori, "Antioxidant micronutrients in the prevention of age-related diseases," Journal of Postgraduate Medicine, vol. 49, no. 3, pp. 229-235, 2003. 
[75] A. L. Fanciullino, M. Cercós, C. Dhuique-Mayer et al., “Changes in carotenoid content and biosynthetic gene expression in juice sacs of four orange varieties (Citrus sinensis) differing in flesh fruit color," Journal of Agricultural and Food Chemistry, vol. 56, no. 10, pp. 3628-3638, 2008.

[76] H. Tapiero, D. M. Townsend, and K. D. Tew, "The role of carotenoids in the prevention of human pathologies," Biomedicine and Pharmacotherapy, vol. 58, no. 2, pp. 100-110, 2004.

[77] S. K. Osganian, M. J. Stampfer, E. Rimm, D. Spiegelman, J. E. Manson, and W. C. Willett, "Dietary carotenoids and risk of coronary artery disease in women," The American Journal of Clinical Nutrition, vol. 77, no. 6, pp. 1390-1399, 2003.

[78] K. Klipstein-Grobusch, J. M. Geleijnse, J. H. den Breeijen et al., "Dietary antioxidants and risk of myocardial infarction in the elderly: the Rotterdam study," The American Journal of Clinical Nutrition, vol. 69, no. 2, pp. 261-266, 1999.

[79] A. Tavani, E. Negri, B. D’Avanzo, and C. La Vecchia, “ $\beta$-carotene intake and risk of nonfatal acute myocardial infarction in women," European Journal of Epidemiology, vol. 13, no. 6, pp. 631-637, 1997.

[80] A. Cherubini, G. Zuliani, F. Costantini et al., "High vitamin E plasma levels and low low-density lipoprotein oxidation are associated with the absence of atherosclerosis in octogenarians," Journal of the American Geriatrics Society, vol. 49, no. 5, pp. 651654, 2001.

[81] A. Cherubini, M. C. Polidori, M. Bregnocchi et al., "Antioxidant profile and early outcome in stroke patients," Stroke, vol. 31, no. 10, pp. 2295-2300, 2000.

[82] M. C. Polidori, A. Cherubini, W. Stahl, U. Senin, H. Sies, and P. Mecocci, "Plasma carotenoid and malondialdehyde levels in ischemic stroke patients: relationship to early outcome," Free Radical Research, vol. 36, no. 3, pp. 265-268, 2002.

[83] A. Ascherio, E. B. Rimm, M. A. Hernán et al., "Relation of consumption of vitamin E, vitamin C, and carotenoids to risk for stroke among men in the United States," Annals of Internal Medicine, vol. 130, no. 12, pp. 963-970, 1999.

[84] P. Knekt, J. Ritz, M. A. Pereira et al., "Antioxidant vitamins and coronary heart disease risk: a pooled analysis of 9 cohorts," The American Journal of Clinical Nutrition, vol. 80, no. 6, pp. 15081520, 2004.

[85] O. P. Heinonen and D. Albanes, "The effect of vitamin $\mathrm{E}$ and $\beta$ carotene on the incidence of lung cancer and other cancers in male smokers," The New England Journal of Medicine, vol. 330, no. 15, pp. 1029-1035, 1994.

[86] C. H. Hennekens, J. E. Buring, J. E. Manson et al., "Lack of effect of long-term supplementation with $\beta$ carotene on the incidence of malignant neoplasms and cardiovascular disease," The New England Journal of Medicine, vol. 334, no. 18, pp. 1145-1149, 1996.

[87] J. Virtamo, P. Pietinen, J. K. Huttunen et al., "Incidence of cancer and mortality following $\alpha$-tocopherol and $\beta$-carotene supplementation: a postintervention follow-up," The Journal of the American Medical Association, vol. 290, no. 4, pp. 476-485, 2003.

[88] G. S. Omenn, G. E. Goodman, M. D. Thornquist et al., "Effects of a combination of $\beta$ carotene and vitamin A on lung cancer and cardiovascular disease," The New England Journal of Medicine, vol. 334, no. 18, pp. 1150-1155, 1996.

[89] C. D. Morris and S. Carson, "Routine vitamin supplementation to prevent cardiovascular disease: a summary of the evidence for the U.S. preventive services task force," Annals of Internal Medicine, vol. 139, no. 1, pp. 56-70, 2003.
[90] M. G. Traber and J. F. Stevens, "Vitamins C and E: beneficial effects from a mechanistic perspective," Free Radical Biology and Medicine, vol. 51, no. 5, pp. 1000-1013, 2011.

[91] A. Carr and B. Frei, "Does vitamin C act as a pro-oxidant under physiological conditions?” FASEB Journal, vol. 13, no. 9, pp. 1007-1024, 1999.

[92] G. R. Buettner, "The pecking order of free radicals and antioxidants: lipid peroxidation, $\alpha$-tocopherol, and ascorbate," Archives of Biochemistry and Biophysics, vol. 300, no. 2, pp. 535-543, 1993.

[93] N. Gokce, J. F. Keaney, B. Frei et al., "Long-term ascorbic acid administration reverses endothelial vasomotor dysfunction in patients with coronary artery disease," Circulation, vol. 99, no. 25, pp. 3234-3240, 1999.

[94] R. H. Alul, M. Wood, J. Longo et al., "Vitamin C protects lowdensity lipoprotein from homocysteine-mediated oxidation," Free Radical Biology and Medicine, vol. 34, no. 7, pp. 881-891, 2003.

[95] A. C. Carr and B. Frei, "Human neutrophils oxidize low-density lipoprotein by a hypochlorous acid-dependent mechanism: the role of vitamin C," Biological Chemistry, vol. 383, no. 3-4, pp. 627-636, 2002.

[96] A. Martin and B. Frei, "Both intracellular and extracellular vitamin $C$ inhibit atherogenic modification of LDL by human vascular endothelial cells," Arteriosclerosis, Thrombosis, and Vascular Biology, vol. 17, no. 8, pp. 1583-1590, 1997.

[97] R. C. M. Siow, J. P. Richards, K. C. Pedley, D. S. Leake, and G. E. Mann, "Vitamin C protects human vascular smooth muscle cells against apoptosis induced by moderately oxidized LDL containing high levels of lipid hydroperoxides," Arteriosclerosis, Thrombosis, and Vascular Biology, vol. 19, no. 10, pp. 2387-2394, 1999.

[98] R. Asmis and E. S. Wintergerst, "Dehydroascorbic acid prevents apoptosis induced by oxidized low-density lipoprotein in human monocyte-derived macrophages," European Journal of Biochemistry, vol. 255, no. 1, pp. 147-155, 1998.

[99] E. A. Lutsenko, J. M. Cárcamo, and D. W. Golde, "Vitamin C prevents DNA mutation induced by oxidative stress," The Journal of Biological Chemistry, vol. 277, no. 19, pp. 16895-16899, 2002.

[100] M. Noroozi, W. J. Angerson, and M. E. J. Lean, "Effects of flavonoids and vitamin C on oxidative DNA damage to human lymphocytes," The American Journal of Clinical Nutrition, vol. 67, no. 6, pp. 1210-1218, 1998.

[101] M. Pflaum, C. Kielbassa, M. Garmyn, and B. Epe, "Oxidative DNA damage induced by visible light in mammalian cells: extent, inhibition by antioxidants and genotoxic effects," Mutation Research - DNA Repair, vol. 408, no. 2, pp. 137-146, 1998.

[102] S. F. Sweetman, J. J. Strain, and V. J. McKelvey-Martin, "Effect of antioxidant vitamin supplementation on DNA damage and repair in human lymphoblastoid cells," Nutrition and Cancer, vol. 27, no. 2, pp. 122-130, 1997.

[103] H. J. Thompson, J. Heimendinger, A. Haegele et al., "Effect of increased vegetable and fruit consumption on markers of oxidative cellular damage," Carcinogenesis, vol. 20, no. 12, pp. 22612266, 1999.

[104] P. Rapisarda, G. Carollo, B. Fallico, F. Tomaselli, and E. Maccarone, "Hydroxycinnamic acids as markers of Italian blood orange juices," Journal of Agricultural and Food Chemistry, vol. 46, no. 2, pp. 464-470, 1998.

[105] L. W. Zhang, S. A. Al-Suwayeh, P. W. Hsieh, and J. Y. Fang, "A comparison of skin delivery of ferulic acid and its derivatives: 
evaluation of their efficacy and safety," International Journal of Pharmaceutics, vol. 399, no. 1-2, pp. 44-51, 2010.

[106] A. Saija, A. Tomaino, D. Trombetta et al., "In vitro and in vivo evaluation of caffeic and ferulic acids as topical photoprotective agents," International Journal of Pharmaceutics, vol. 199, no. 1, pp. 39-47, 2000.

[107] C. Oresajo, T. Stephens, P. D. Hino et al., "Protective effects of a topical antioxidant mixture containing vitamin $\mathrm{C}$, ferulic acid, and phloretin against ultraviolet-induced photodamage in human skin," Journal of Cosmetic Dermatology, vol. 7, no. 4, pp. 290-297, 2008.

[108] J. Shanthakumar, A. Karthikeyan, V. R. Bandugula, and P. N. Rajendra, "Ferulic acid, a dietary phenolic acid, modulates radiation effects in Swiss albino mice," European Journal of Pharmacology, vol. 691, no. 1-3, pp. 268-274, 2012.

[109] N. Baskaran, S. Manoharan, S. Balakrishnan, and P. Pugalendhi, "Chemopreventive potential of ferulic acid in 7,12-dimethylbenz[a]anthracene-induced mammary carcinogenesis in Sprague-Dawley rats," European Journal of Pharmacology, vol. 637, no. 1-3, pp. 22-29, 2010.

[110] S. Balakrishnan, V. P. Menon, and S. Manoharan, "Ferulic acid inhibits 7,12-dimethylbenz $[\alpha]$ anthracene-induced hamster buccal pouch carcinogenesis," Journal of Medicinal Food, vol. 11, no. 4, pp. 693-700, 2008.

[111] S. Miyamoto, F. Epifano, M. Curini et al., "A novel prodrug of 4/-geranyloxy-ferulic acid suppresses colitis-related colon carcinogenesis in mice," Nutrition and Cancer, vol. 60, no. 5, pp. 675-684, 2008.

[112] A. Murakami, Y. Nakamura, K. Koshimizu et al., "FA15, a hydrophobic derivative of ferulic acid, suppresses inflammatory responses and skin tumor promotion: comparison with ferulic acid," Cancer Letters, vol. 180, no. 2, pp. 121-129, 2002.

[113] W. Boerjan, J. Ralph, and M. Baucher, "Lignin biosynthesis," Annual Review of Plant Biology, vol. 54, pp. 519-546, 2003.

[114] Y. J. Chen, M. S. Shiao, and S. Y. Wang, "The antioxidant caffeic acid phenethyl ester induces apoptosis associated with selective scavenging of hydrogen peroxide in human leukemic HL-60 cells," Anti-Cancer Drugs, vol. 12, no. 2, pp. 143-149, 2001.

[115] M. Esrefoglu, M. Iraz, B. Ates, and M. Gul, "Not only melatonin but also caffeic acid phenethyl ester protects kidneys against aging-related oxidative damage in Sprague Dawley rats," Ultrastructural Pathology, vol. 36, no. 4, pp. 244-251, 2012.

[116] F. Ozguner, F. Oktem, A. Armagan et al., "Comparative analysis of the protective effects of melatonin and caffeic acid phenethyl ester (CAPE) on mobile phone-induced renal impairment in rat," Molecular and Cellular Biochemistry, vol. 276, no. 1-2, pp. 31-37, 2005.

[117] S. Celik, S. Gorur, O. Aslantas, S. Erdogan, S. Ocak, and S. Hakverdi, "Caffeic acid phenethyl ester suppresses oxidative stress in Escherichia coli-induced pyelonephritis in rats," Molecular and Cellular Biochemistry, vol. 297, no. 1-2, pp.131-138, 2007.

[118] F. Ozguner, Y. Bardak, and S. Comlekci, "Protective effects of melatonin and caffeic acid phenethyl ester against retinal oxidative stress in long-term use of mobile phone: a comparative study," Molecular and Cellular Biochemistry, vol. 282, no. 1-2, pp. 83-88, 2006.

[119] F. Ozguner, A. Altinbas, M. Ozaydin et al., "Mobile phoneinduced myocardial oxidative stress: protection by a novel antioxidant agent caffeic acid phenethyl ester," Toxicology and Industrial Health, vol. 21, no. 9, pp. 223-230, 2005.

[120] M. Esrefoglu, M. Gul, B. Ates, and A. Erdogan, "The effects of caffeic acid phenethyl ester and melatonin on age-related vascular remodeling and cardiac damage," Fundamental and Clinical Pharmacology, vol. 25, no. 5, pp. 580-590, 2011.

[121] Y. C. Weng, S. T. Chuang, Y. C. Lin et al., "Caffeic acid phenylethyl amide protects against the metabolic consequences in diabetes mellitus induced by diet and streptozocin," EvidenceBased Complementary and Alternative Medicine, vol. 2012, Article ID 984780, 12 pages, 2012.

[122] S. Celik, S. Erdogan, and M. Tuzcu, "Caffeic acid phenethyl ester (CAPE) exhibits significant potential as an antidiabetic and liver-protective agent in streptozotocin-induced diabetic rats," Pharmacological Research, vol. 60, no. 4, pp. 270-276, 2009.

[123] L. Tamer, N. Sucu, B. Ercan et al., "The effects of the caffeic acid phenethyl ester (CAPE) on erythrocyte membrane damage after hind limb ischaemia-reperfusion," Cell Biochemistry and Function, vol. 22, no. 5, pp. 287-290, 2004.

[124] N. Cengiz, N. Colakoglu, A. Kavakli, E. Sahna, H. Parlakpinar, and A. Acet, "Effects of caffeic acid phenethyl ester on cerebral cortex: structural changes resulting from middle cerebral artery ischemia reperfusion," Clinical Neuropathology, vol. 26, no. 2, pp. 80-84, 2007.

[125] S. Celik and S. Erdogan, "Caffeic acid phenethyl ester (CAPE) protects brain against oxidative stress and inflammation induced by diabetes in rats," Molecular and Cellular Biochemistry, vol. 312, no. 1-2, pp. 39-46, 2008.

[126] H. R. Yilmaz, E. Uz, N. Yucel, I. Altuntas, and N. Ozcelik, "Protective effect of caffeic acid phenethyl ester (CAPE) on lipid peroxidation and antioxidant enzymes in diabetic rat liver," Journal of Biochemical and Molecular Toxicology, vol. 18, no. 4, pp. 234-238, 2004.

[127] P. Michaluart, J. L. Masferrer, A. M. Carothers et al., "Inhibitory effects of caffeic acid phenethyl ester on the activity and expression of cyclooxygenase-2 in human oral epithelial cells and in a rat model of inflammation," Cancer Research, vol. 59, no. 10, pp. 2347-2352, 1999.

[128] W. K. Jung, I. Choi, D. Y. Lee et al., "Caffeic acid phenethyl ester protects mice from lethal endotoxin shock and inhibits lipopolysaccharide-induced cyclooxygenase- 2 and inducible nitric oxide synthase expression in RAW 264.7 macrophages via the p38/ERK and NF- $\kappa$ B pathways," International Journal of Biochemistry and Cell Biology, vol. 40, no. 11, pp. 2572-2582, 2008.

[129] V. T. Foti, A. Scuderi, and G. Timpanaro, "Organic social agricolture: a tool for rural development," Quality-Access to Success, vol. 14, no. 1, pp. 266-271, 2013.

[130] G. Chinnici, B. Pecorino, and A. Scuderi, "Environmental and economic performance of organic citrus growing," QualityAccess to Success, vol. 14, no. 1, pp. 106-112, 2013. 


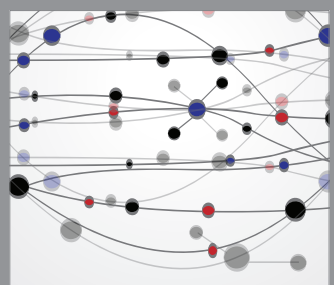

The Scientific World Journal
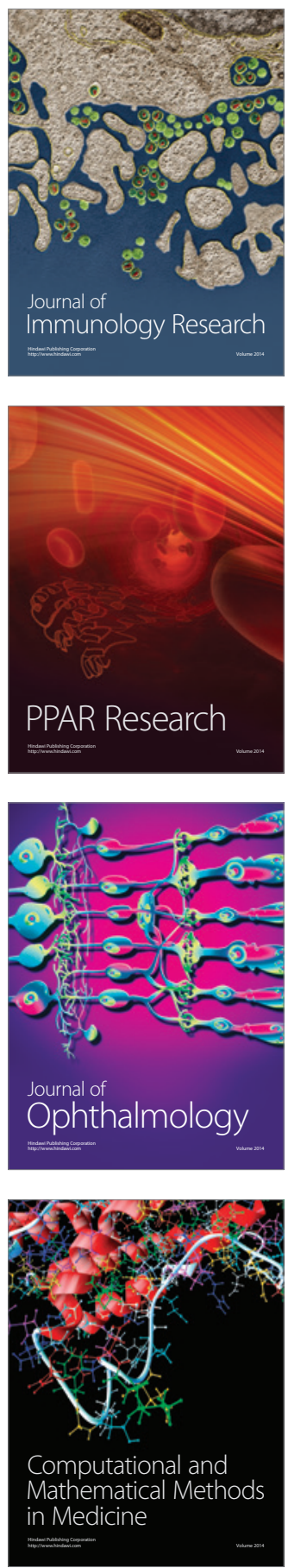

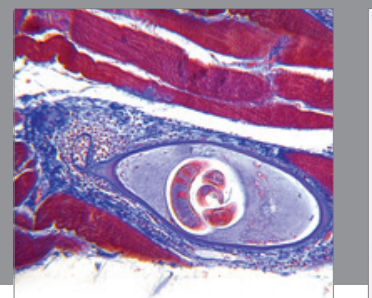

Gastroenterology

Research and Practice
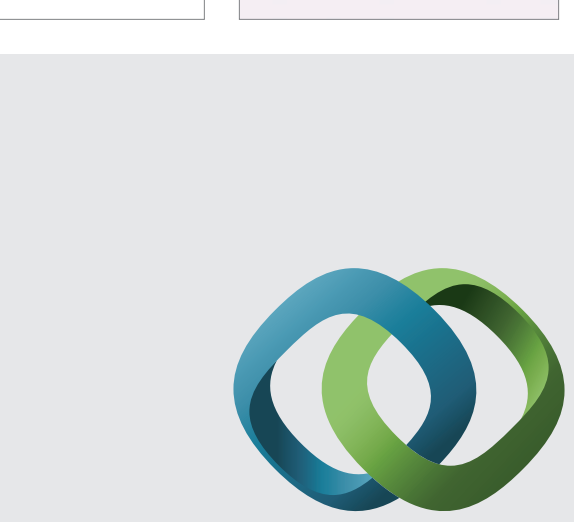

\section{Hindawi}

Submit your manuscripts at

http://www.hindawi.com
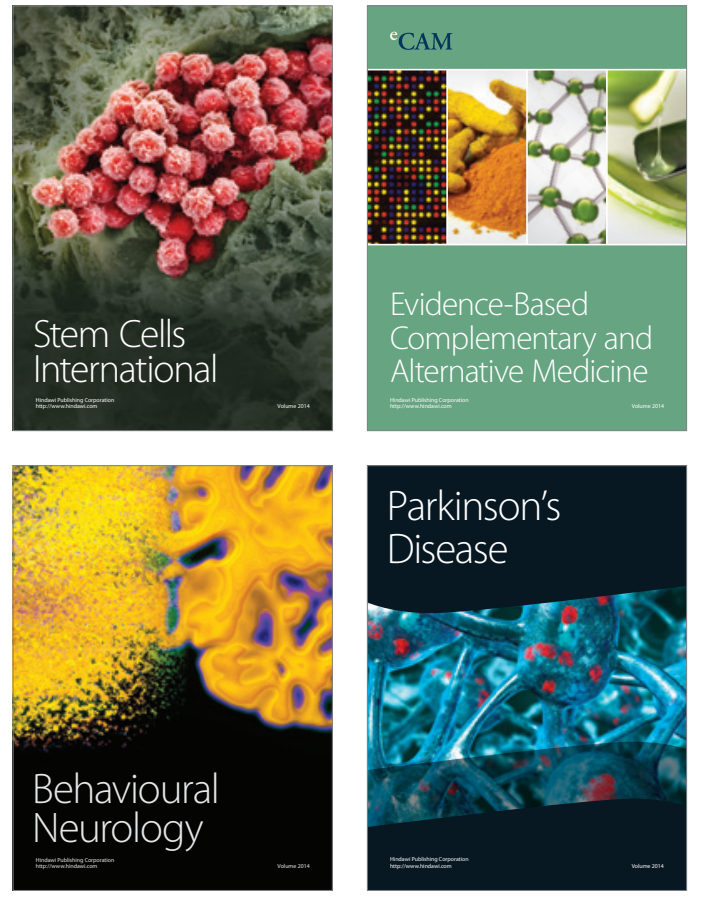
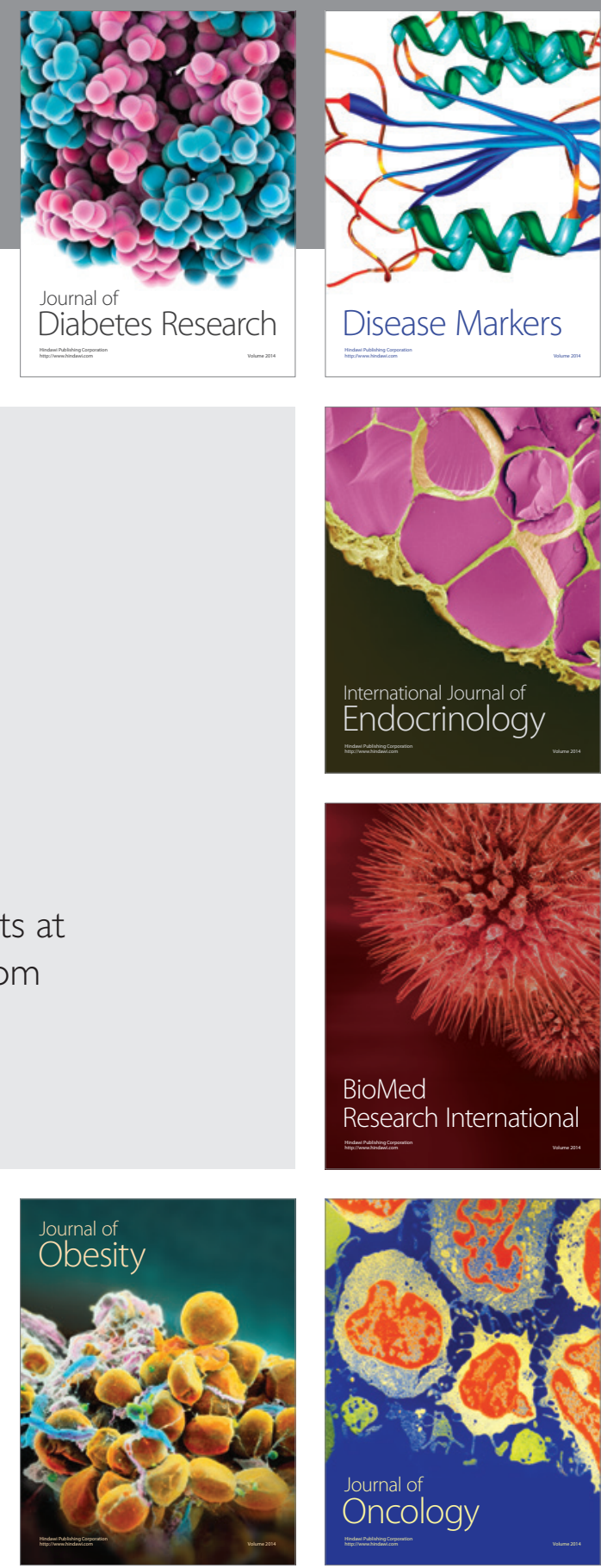

Disease Markers
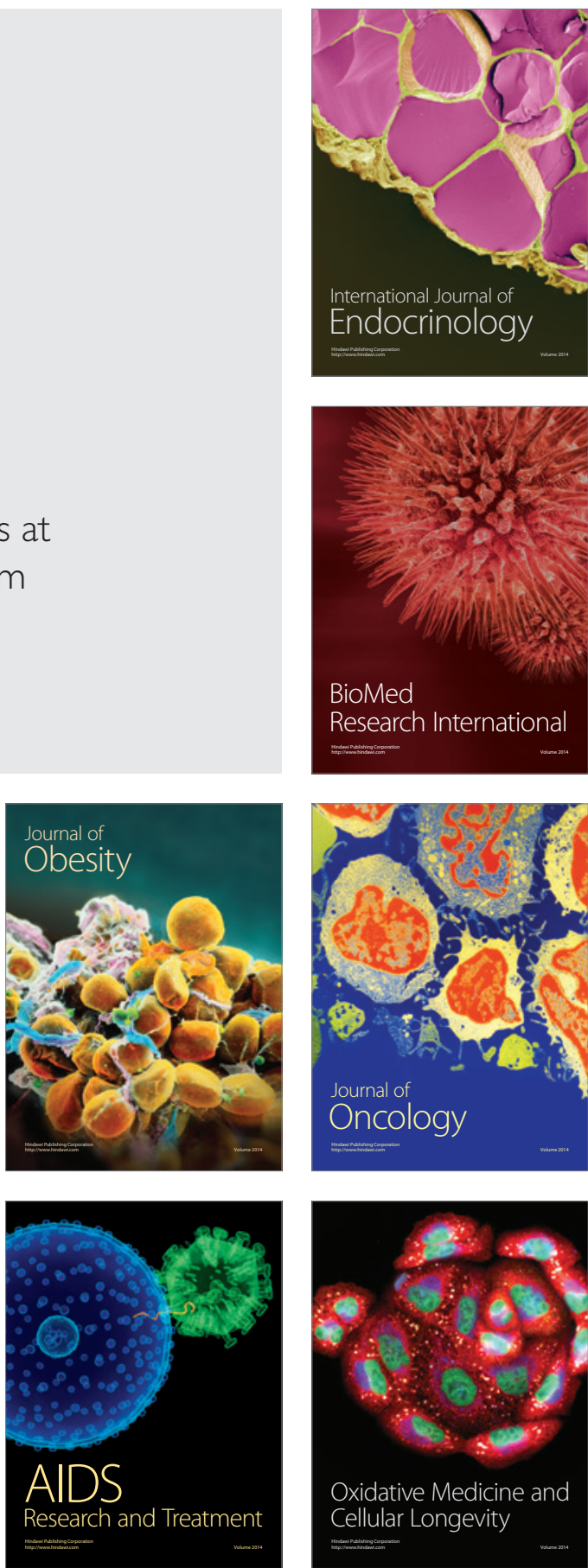